\title{
Drawing Guessing Game for the Elderly
}

\author{
Wai Yip Foo, Woan Ning Lim, Chien Sing Lee \\ Department of Computing and Information Systems \\ School of Science and Technology \\ Sunway University \\ Bandar Sunway, Malaysia. \\ (woanningl@sunway.edu.my, chiensingl@sunway.edu.my )
}

\begin{abstract}
Drawing guessing game is the game where the users are required to guess the item that is progressively drawn on the screen. In this project, an elderly oriented mobile drawing guessing game named Guess It was developed. This application allows the drawings to be added into the cloud database from time to time and get downloaded to the user's mobile devices without the need to update the application. The time taken to complete each game can be recorded to monitor the progress of the elderlies who plays the game. The aim of this project is to develop an elderly friendly mobile game by incorporating the elderly gaming design guidelines and by considering the elderly's limitations, to foster the interest of the elderly in mobile gaming. Survey was carried out with a group of elderlies at the end of the project to gauge their confidence and satisfaction level in the developed game.
\end{abstract}

Key words_-game design; memory; mobile game; elderly

\section{INTRODUCTION}

Interaction is extremely crucial in our daily routine, and it is especially important for elderlies. As we age, we face declination or degeneration not just physically, but mentally as well. Many elderlies are left to suffer loneliness, as their loved ones or anyone that they had affection with slowly fades away from time to time. Long age can be a curse instead of a blessing, without anyone to share their stories with, they may find their lives meaningless. When an elderly has no one to talk to, or they decide to isolate themselves, their cognitive function will decline rapidly, which slowly leads to Alzheimer's disease. The risk of social isolation doesn't just end here, various dysfunctions such as disrupted sleeping, increase blood pressure, and depression will gradually appear. Studies show that health risk is directly proportional to the increase of isolation in our daily routines.

Since the breakthrough of the smartphone, a new era of mobile device emerges and it rapidly took over the world by storm. It marks the evolution of how we use a phone, from an optional gadget, to a necessity. The evolution of smartphone changes our everyday lifestyle, gradually we have become more and more dependent to our mobile devices. We use them to perform daily activities, including work, communication, entertainment, and also research. However, this evolution only draws a greater gap in between us and the older generations. Since we are exposed to technology at a younger age, we tend to adapt faster than the adults and the elderlies. This leads to an isolation of the elderlies as they couldn't keep up with the technology trend.

The research was funded by the Malaysian Ministry of Education's Fundamental Research Grant Scheme FRGS/1/2016/ICT04/SYUC/01/1 (Aug 2016-Jul 2018)
A study was conducted [1] to compare the learning rate of different generations have shown that elderlies tend to have a slower learning rate towards smartphone compared to us youngsters. Through their research, it is founded that the elderlies tend to make more detours and resetting back to the home main menu while trying to solve a task with the smartphone. However, it is also founded that the elderlies tend to outperform the youngsters when it comes to a simpler, less complex Symbian phone. This shows that the elderlies are more comfortable with their classic mobile devices.

Despite the difficulties in learning, research [2] has shown that elderly nowadays are more digitally aware than they used to be 10 years ago. Their motivation comes from 2 major factors, which are the desire to search for information online, and to keep in touch with their children and grandchildren from afar. Projects and efforts from various organization to boost their usage are also one of the key factors of this motivation. It is also found that, among so many gadgets and devices such as computer, tablets and laptops, the elderlies prefer smartphone out of them all.

The research of the design guidelines of mobile gaming for elderly mentioned that the lack of computer literacy would affect the elderlies' confidence in digital gaming [3]. Most elderlies tend to draw relations of negativity influences with digital gaming, such as the violence in the violent digital game would cause youngsters to overreact and ultimately taking their own or someone else's life as reported multiple times on newspapers. This supports the point that the elderlies don't like violent games.

Research findings stated that the elderlies preferred games that are more correlated to their lifestyles [4]. Both the male and female elderlies have different preferences, due to their different lifestyle. It is founded that the female elderlies prefer games such as gardening, or games that requires light physical workout. The male elderlies however preferred more relaxing games such as reading or music. This is aligned with the research survey that found out that games tend to be gender bias [3], for example a game of billiards which they found that only the males would play it. This means that the game was only preferred by a certain gender. This is because that billiard is a more male oriented genre, while we could say the same towards dress up games are more female oriented.

The research [4] also reported that, the elderlies tend to have a nostalgic feeling towards games that they played in their youth 
days, such as card and board games. And, the elderlies would prefer games that doesn't have too much restriction on their time and partner availability.

\section{BENEFITS AND Limitations OF MOBILE GAMING}

One of the clear benefits of mobile gaming towards elderlies is that the elderlies can get some physical workouts from such games that require limited physical works. For example, the recently launched game Pokemon GO took the world by storm and made many people walk around just to capture the Pokemons hidden in the area. Such games are classified as the lowest cost tool for prevention and treatment for various diseases such as diabetes, obesity, and cardiovascular related disease. This is because these actions will cause sweating, which is our natural way of expelling toxins from our body [5].

Alternatively, games that require some gesture movement also works the same way in improving elderly's well-being. The Nintendo Wii is a great innovative gaming platform that does such games, the elderly's can enjoy spending their leisure time on improving their health without leaving the comfort of their homes. This also helps the elderlies to nurture a habit in exercising in a fun way.

Modern treatment includes games being designed and used in the medical area as an aid and treatment. In some cases, it is reported that gaming can be better in diagnosing and treating patients suffering from neuropsychological disease than the traditional methods.

An aspect that the elderly would be interested in benefits of gaming is the interaction and socialization with people. Gaming brings people together no matter what race or generation they are from. Elderlies have a motivational factor of gaming when it is done with their grandchildren, this shows that their desire to communicate with their beloved ones are strong. This can be used as a bridge to enforce their relationships with their relatives and siblings. Ultimately, engagement reduces loneliness and the mental illness that comes after that.

Despite the benefits the elderly can gain from the mobile gaming, there are limitations that need to deal with. Most elderlies may have cardiovascular problems; hence they could not perform task that require much physical work outs or play any game that is too intense. The game design must be able to allow the elderly to set the time pace to their preferences.

Apart from intensive games, some elderly may also have difficulties in moving around. Their mobility is limited due to maybe a stroke that paralyzes part of their body, it can also be due to injuries of their lower back that causes paralysis to their lower body. A more common case is the diabetic disease that causes the numbness in their feet. Generally, even if they do not have possess such disease, elderlies can't be as mobile as they used to be.

The brightness illuminated from the smartphones are sometimes too irritating to the elder's eyes. However, smartphone nowadays comes with automatic brightness control base on the surrounding brightness captured by the front camera acting as a sensor. As we grow older, we will develop long sightedness naturally, therefore when facing something small, the elderlies may find it hard to read from the smartphone's screen. Therefore, a larger screen smartphone is more preferred in this case.

The largest limitation is the cognitive challenges. Since the elderlies are not familiar with a mobile device, building the product on a mobile device platform and expecting them to play with it seems mere impossible. The content of game itself must be satisfying and interesting to the elderly else they would just give up after a few attempts.

\section{FEATURES OF THE DRAWING GUESSING GAME}

With careful considerations and multiple researches done, the drawing-guessing game was chosen because drawing is a fundamental knowledge of a human being, we are taught to draw before we are taught to write; hence no new skill needs to be acquired by the elderly to play this game. The drawing skills of a person may vary but it doesn't have to be perfect in this game because the drawer can use different style of approach to express the words that they are supposed to draw. The elderlies are required to use their problem solving analytic skills to relate what the drawing is and try to answer it. The only technique required here is to teach the elderly how to navigate through interface of the game. Although the way to play the game is simple, the game can provide different level of difficulties by incorporating simple tangible words and difficult intangible words for guessing. And the game can easily relate to the elderlies' daily activities by incorporating the words that the elderlies are familiar with.

Every guessing drawing game will come with these basic standard features such as timer, word indicator, drawing tools, and chat box. However, to make the game more interactive and easier for the elderlies, these standard features must be more elaborated. The design must be simple, yet attractive enough to capture the interest of the elderlies.

Word indicator is a feature to hint the number of letters that the players are supposed to guess. This helps to increase the possibilities to win as the elderlies know how many letters in the word that they are guessing. All the guessing game incorporated this, but this feature was improved in this project. As time passes, a random letter of the entire word will be displayed. Displaying the letter can help the elderlies compare their word in mind with the letter whether it matches. For example, the players have to guess a 7 letters word, as time passes the fifth letter is revealed to be a 'I', the players can now draw relation from the revealed letter with the image being drawn on the drawing board.

The pop up message feature is probably the most under looked and undervalued feature by most developers. It can be used to inform the player on the action they should take. The pop up message feature can also be used to inform the player the guessing result, and display the winning score. However, some may find it annoying because once it pops up, the player must stop whatever they are doing and click away the notification. More experienced players find it unnecessary as this would obstruct the smoothness of the game. However, considering that we are targeting elderlies who are lack in computer literacy, this feature can be used as a guide to navigate them by giving them step by step instructions. This solves most of the confusion faced 
and in a long run may boost their confidence in electronic gaming.

To keep track of the time and let players know how much time they have left to guess, a timer is always included in the game. However, many games do not allow customizable timing. In this guessing-drawing game, the difficulty of the game is adjustable. Elderly with limited English literacy may take a longer time in guessing the picture, therefore a longer time span should be given for the amateur players. As they get better in the game, a short time span will be set for the for a more challenging gameplay. It is good to have such option available rather than having a rigid style. As discussed, elderlies prefer a game that is customizable, thus this feature is desirable.

\section{DESIGN GUIDELINES OF MOBILE GAMES FOR ELDERLY}

In the process of developing the game for elderlies, there were a few recommendations and guidelines to follow. Among the guidelines [6], one of them is to provide instant feedback to the player. The elderly can be aware of their course of action and the result of it, they are then able to adjust themselves to obtain a better outcome on the next attempt. One example on instant feedback is the error alert that would be played to the user when the user answers incorrectly, the elderly will be aware that his/her answer is faulty and will instantly search for another answer.

Another guideline is not to overcomplicate the game, the design must be simple, yet the game must be fun to play with. A clear goal must be given such as to achieve the highest score out of the competitors, this gives motivation to the elderlies to put in effort and brainstorm to carry out the objective. This is due to the cognitive functions of the elderlies that declines from aging, they are not as attentive as a player who is at his/her prime age. Other than that, their ability to reason, memory capabilities, and comprehension is in decline. Therefore, the choice of words for the game must not be too difficult to frustrate them, but be challenging enough to bring them joy whenever they play.

Motor impairments are very diverse among the elders, most of them do have it by some common causes. However, the level of motor impairments is wide in scale. It is best to avoid designing buttons that are too small to be clicked, texts that are too small to read, and videos that are too small to see. Although mobile devices are generally compact and small, the design for the games on the mobile devices should be able to accommodate elders with different motor impairment levels.

Personal preferences or customizability of the game is important as to adjust the game level to suit the elderlies pace. This also allows the elderly to modify the game settings so that it won't be too dull as they got use to the game. Some elderlies may not have to ability to read or speak fluent English, their education background varies widely, and some of they may be illiterate. Ability to select their preferred language as the ingame language can help them remove the hindrance of the language barrier. Another way to cater for players with different education background or illiterate players is to design the animation to be self-explanatory that doesn't require words.

The game should avoid complicated interface mechanism and provide guidelines for what to do next to avoid frustration.
The elderlies may make some mistakes as they play the game, a pop up message is necessary to have to tell the user the proper step to take or the valid data to enter. Informing and congratulating the player for scoring a new high score or winning the game is another good implementation that can be done for a better interaction mechanism. Elderlies will prefer game that has a purpose, such as fostering relationships. Examples of good interface mechanism is to display the player's username and necessary information such as their score.

\section{V. 'GUESS IT' APPLICATION OVERVIEW}

The game developed in this project is named Guess It. The user registration feature in this game has been simplified in consideration of the elderlies. The user will just have to enter their desired username and login without the needs of any email or password. Logging in is required to record the time taken to complete a specific drawing video, this helps to keep track of how well the elderlies have done on the game, and notify them if they have improved from the last play.

The gameplay is very straightforward and simple; It requires the player to guess the item that the person is drawing in the video in a limited amount of time. The faster the user can answer the question the better the score. Every game's new high score will be recorded associated to the username of the account. If the user fails to answer the video within the time limit, then no score will be awarded. However, if there is still time, the user is required to try and try again until the time is up or the user gets the correct answer. Hints will be revealed to the user overtime to guide them and ease the process. The game requires Internet access to connect and retrieve data and videos from the database storages, it is unable to proceed without it.

Guess It is a game designed to challenge and improve the elderlies' problem solving skills and memory capabilities overtime as they try to identify the new drawings added into the game overtime and replay and recall the drawings that they previously played.

The Guess It game application design is shown in Fig. 1.

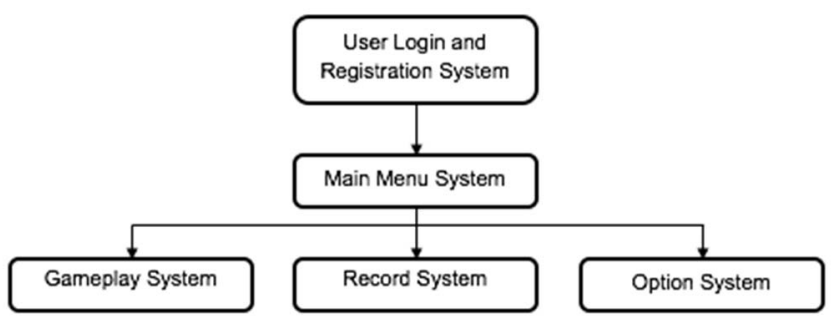

Fig. 1. Guess It application design.

\section{A. User Login and Registration}

This component handles the task of user login and registration. When the user launches the application, the user shall first be presented to this page (Fig. 2) for authentication purposes. Although the authentication is simple which does not require any password associated to the user account, it serves as a placeholder for the user to keep his/her record of high scores. The entire system requires Internet access to communicate with 
the server, if the user not have Internet access, the user shall not be able to login or register his/her account.

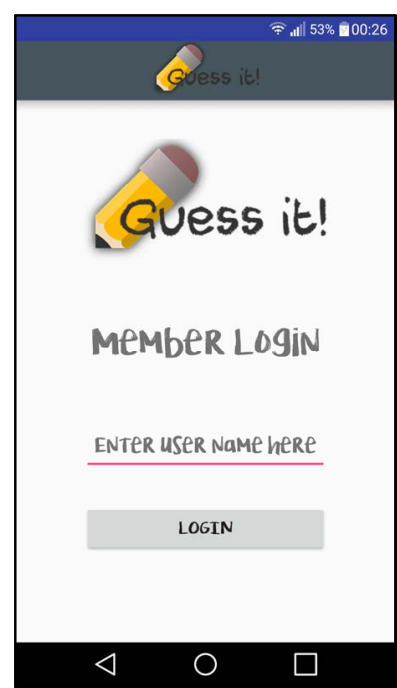

Fig. 2. User login and registration page.

\section{B. Main Menu}

This component is the landing page for the user, to allow them to navigate around the application. User shall be able to navigate to the Gameplay, Record, and Option System via this page (Fig. 3). The user shall also be able to navigate from any of the system ahead and back to this page or back to the login and registration page.

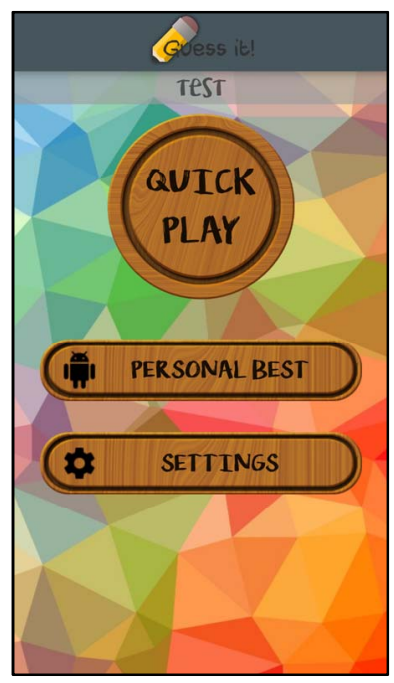

Fig. 3. Main menu page.

\section{Gameplay}

This is the main component of the entire system, which controls the entire flow of the gameplay. When this page is loaded, it will communicate and download the drawing videos from the cloud database storage to be played back for the user to guess. As soon as the drawing video has finished downloading, the game will start playing the video, and start the timer (Fig. 4). During the game, it will compare the user's answer with the correct answer and provide feedback to the user. If the answer is correct, the system will proceed with the next drawing video.
The time taken to complete the game will be recorded if it is better than the user's previous high score. However, if the user answers incorrectly, the system will provide an error feedback and tell the user to try again. When the allocated time runs out, the current game will end and next game will commence.

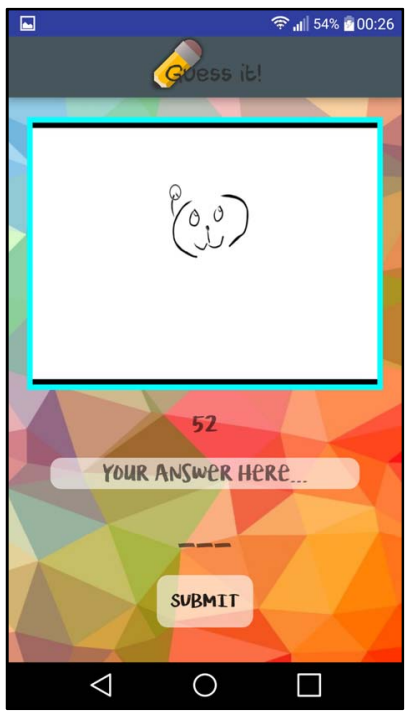

Fig. 4. Gameplay page.

\section{History Record}

This component communicates with the cloud database to retrieve and display the history records of the completing time for all the games that the user has played (Fig. 5).

\begin{tabular}{|lc|}
\hline & Guess it! \\
android & $50 \mathrm{~s}$ \\
apparel & $1 \mathrm{~s}$ \\
burger & $1 \mathrm{~s}$ \\
candy & $53 \mathrm{~s}$ \\
deer & $20 \mathrm{~s}$ \\
dog & $1 \mathrm{~s}$ \\
\hline eye & $43 \mathrm{~s}$ \\
\hline
\end{tabular}

Fig. 5. History record page.

\section{E. Settings}

This component allows the user to tweak and configure the application's features to their preferences (Fig. 6). User can adjust the brightness and volume of the game in this system. The system also allows user to log out his/her account and close the application. 


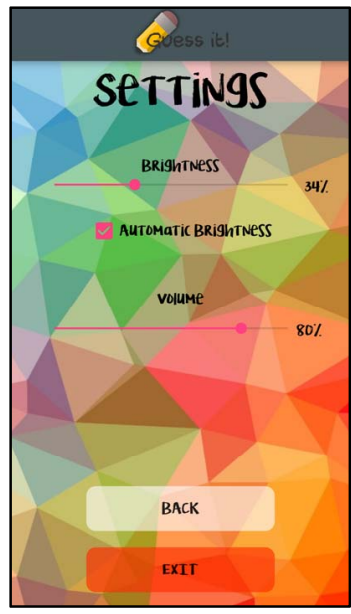

Fig. 6. Settings page.

\section{RESULTS DISCUSSION}

Survey has been conducted among the elderlies to analyze the confidence and acceptance level of the elderly on playing this Guess It game. Survey questionnaire consists of 13 questions based on the ARCS (Attention, Relevance, Confidence, Satisfaction) model [7] was used as listed in TABLE I. The questionnaires are in a form of Seven-point Likert scale, with 1 as 'Strongly Negative' and 7 as 'Strongly Positive'.

TABLE I. SURVEY QUESTIONS

\begin{tabular}{|c|c|}
\hline & Cognitive \\
\hline Q1 & I use a lot of mental effort to finish [the task]. \\
\hline \multirow[t]{2}{*}{ Q2 } & $\begin{array}{l}\text { Please indicate the degree of difficulty level in completing [the } \\
\text { task]. }\end{array}$ \\
\hline & Attention \\
\hline Q3 & $\begin{array}{l}\text { The activities required to complete [the task] holds my } \\
\text { attention. }\end{array}$ \\
\hline Q4 & [The task] has things that stimulated my curiosity. \\
\hline Q5 & The variety of activities in [the task] keep my attention. \\
\hline \multirow[t]{2}{*}{ Q6 } & $\begin{array}{l}\text { The flexibility in customizing the activities encourages me to } \\
\text { engage more with the activities. }\end{array}$ \\
\hline & Relevance \\
\hline Q7 & $\begin{array}{l}\text { The activities are clear to me as I understand how to do [the task } \\
\text { in order to clear the activities. }\end{array}$ \\
\hline Q8 & $\begin{array}{l}\text { I could relate [the task] to things I have seen, done or thought } \\
\text { about in my own life. }\end{array}$ \\
\hline \multirow[t]{2}{*}{ Q9 } & $\begin{array}{l}\text { There are sufficient instructions that showed me how to perform } \\
\text { [the task]. }\end{array}$ \\
\hline & Confidence \\
\hline Q10 & I was positive that I have the ability to perform [the task]. \\
\hline Q11 & I was confident that I could complete [the task]. \\
\hline \multirow[t]{2}{*}{ Q12 } & The activities are challenging to me. \\
\hline & Satisfaction \\
\hline Q13 & $\begin{array}{l}\text { In overall, how do you feel about your overall experience in } \\
\text { completing [the task]? }\end{array}$ \\
\hline
\end{tabular}

There were total 10 survey responses collected and the results are shown in TABLE II and Fig. 7.

TABLE II. CUMulative Number of SCORE By Question

\begin{tabular}{l|rrrrrrrrrrrrr}
\hline & Q1 & Q2 & Q3 & Q4 & Q5 & Q6 & Q7 & Q8 & Q9 & Q10 & Q11 & Q12 & Q13 \\
\hline Score 1 & 0 & 1 & 0 & 0 & 0 & 0 & 0 & 1 & 0 & 0 & 0 & 0 & 0 \\
\hline Score 2 & 0 & 0 & 2 & 2 & 1 & 0 & 0 & 0 & 1 & 1 & 2 & 1 & 0 \\
\hline Score 3 & 4 & 4 & 2 & 2 & 2 & 2 & 3 & 2 & 1 & 1 & 0 & 0 & 1 \\
\hline Score 4 & 1 & 3 & 1 & 1 & 1 & 3 & 3 & 1 & 2 & 2 & 1 & 3 & 3 \\
\hline Score 5 & 5 & 1 & 3 & 2 & 3 & 5 & 3 & 5 & 4 & 4 & 5 & 5 & 3 \\
\hline Score 6 & 0 & 1 & 1 & 2 & 3 & 0 & 1 & 1 & 2 & 2 & 2 & 1 & 2 \\
\hline Score 7 & 0 & 0 & 1 & 1 & 0 & 0 & 0 & 0 & 0 & 0 & 0 & 0 & 1 \\
\hline
\end{tabular}

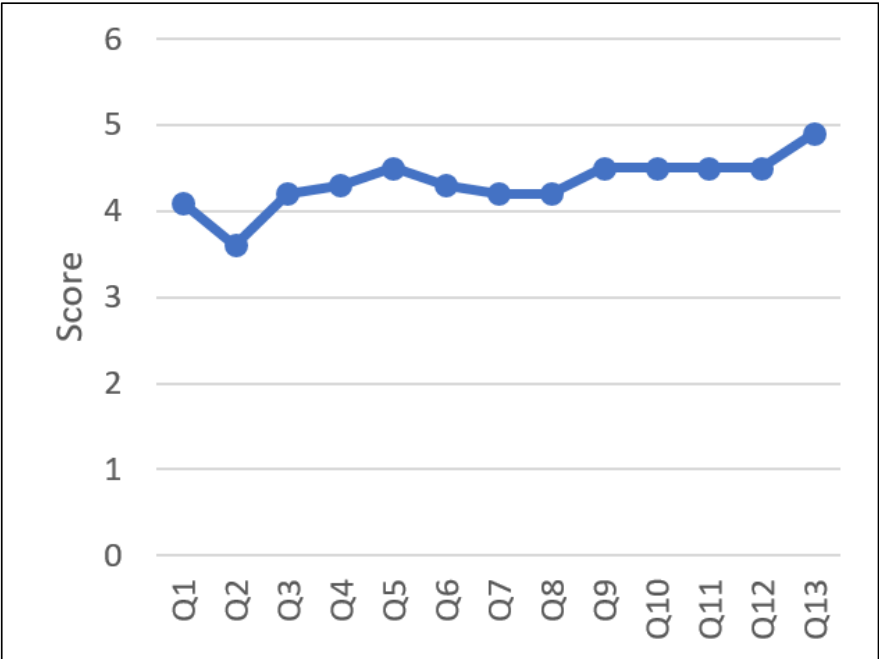

Fig. 7. Mean of score.

The overall responses are positive with the mean of score above 4. It is observed that Q5 and Q13 have the highest score which indicates that the elderlies were attracted to the game by the variety of drawing videos and it did keep their attention well. And the elderly had high overall satisfaction on playing the Guess It game. Q2 has the lowest score which indicates that most of the elderly thought the game is easy for them. This was due to most of the drawing videos were about tangible items and non-abstract words, hence it is easier for the elderly to guess. More abstracts and intangible words can be considered to be incorporated into the game to motivate the interest of the elderly to play the game.

Correlation of the variables is the most appropriate data analysis method to be used upon the gathered data. Correlation is a calculation of how two variables would be significantly related to each other. In this project, the two variables that are analyzed is the positivity in the elderlies' confidence that they could complete the task given to them and the level of satisfactory the elderlies had after going through the game. The hypothesis is, if the given game is easy enough to provide them a small sense of confidence, they will have the interest to go through it and the experience for them will be pleasing overall. 
The null hypothesis made must be proofed positive by the result of the relation of the two variables. Determination of positivity can be proof by achieving a score greater than 0 in the calculation. In order to achieve that, the scores associated to the two variables must be close to equal. For example: A higher score in the user confidence would result in a higher score of the user overall experience, and vice versa. The calculation of the correlation of the two variables is done by using the formula as in (1):

$$
r=\frac{N \sum x y-\left(\sum x\right)\left(\sum y\right)}{\sqrt{\left[N \sum x^{2}-\left(\sum x\right)^{2}\right]\left[N \sum y^{2}-\left(\sum y\right)^{2}\right]}}
$$

Where,

$$
\begin{aligned}
& N=\text { number of pairs of scores } \\
& x=\text { the } \mathrm{x} \text {-variable score } \\
& y=\text { the } \mathrm{y} \text {-variable score }
\end{aligned}
$$

The results of the confidence (x-variable) and satisfaction ( $y$ variable) scores collected from the surveys are shown in TABLE III, and the correlation results are shown in TABLE IV.

TABLE III. SURVEY DATA OF CONFIDENCE AND SATISFACTION

\begin{tabular}{c|cc}
\hline Participants & Confidence & Satisfaction \\
\hline 1 & 5.0 & 6.8 \\
\hline 2 & 3.3 & 4.0 \\
\hline 3 & 4.7 & 4.0 \\
\hline 4 & 4.7 & 5.8 \\
\hline 5 & 4.3 & 4.0 \\
\hline 6 & 5.3 & 5.0 \\
\hline 7 & 5.0 & 5.0 \\
\hline 8 & 5.7 & 6.3 \\
\hline 9 & 4.0 & 5.3 \\
\hline 10 & 3.0 & 3.0 \\
\hline
\end{tabular}

TABLE IV. MULTIVARIATE LINEAR REGRESSION ANALYSIS OF CONFIDENCE SCORES AND SATISFACTION SCORES

\begin{tabular}{lr}
\hline \multicolumn{2}{c}{ Regression Statistics } \\
\hline Multiple R & $\mathbf{0 . 7 3 1 4}$ \\
R Square & 0.5350 \\
Adjusted R Square & 0.4769 \\
Standard Error & 0.8404 \\
Observations & 10 \\
\hline
\end{tabular}

\begin{tabular}{lrrrrr} 
ANOVA & \multicolumn{1}{c}{ SS } & \multicolumn{1}{c}{ MS } & \multicolumn{1}{c}{$F$} & Significance $F$ \\
\hline Regression & 1 & 6.5 & 6.5 & 9.2035 & $\mathbf{0 . 0 1 6 2}$ \\
Residual & 8 & 5.65 & 0.7063 & & \\
Total & 9 & 12.15 & & & \\
\hline
\end{tabular}

It is observed that a significant correlation of confidence and satisfaction is found at $r=.7314, \mathrm{p}<.02$. This shows a very strong positive relation of the two variables. Therefore, this supports the hypothesis of the increase in the elderlies' confidence in playing the game will improve their overall satisfaction and user experience.

\section{CONCLUSION}

The modernization and advancement of technology not only brought great innovations to our life but also turned mobile gaming into a cheap and fun tool to keep the elderlies entertained and mentally healthy. Elderlies often require much physical affection from the friends and families around them, however, not all of them are available at any time. Providing them with a game that challenge their problem solving skills and memory capability can keep them healthy and remain active.

It is a challenging task to design a mobile game that appealing to most of the elderlies, in the consideration of the not boring yet easy to navigate interface design, game contents that can be related to the elderlies' daily activities and elderlies' limitations such as motor impairments, cognitive and computer illiteracy.

In general, the elderlies had responded positively towards the Guess It game. The strong correlation result of confidence and satisfaction confirms the hypothesis of the increase in the elderlies' confidence in playing the game will improve their overall satisfaction. Future works are to be done to engage a bigger tester group to confirm the above findings.

\section{ACKNOWLEDGMENT}

Thanks to Sunway University, Assoc. Prof. Dr. Wong Siew Fan and Assoc. Prof. Dr. Lee Yun Li for contribution in the earlier discussions.

\section{REFERENCES}

[1] M. Ziefle and S. Bay, "How older adults meet complexity: Aging effects on the usability of different mobile phones", Behaviour \& Information Technology, vol. 24, no. 5, pp. 375-389, 2005.

[2] B. Klimova and P. Maresova, "Elderly People and Their Attitude Towards Mobile Phones and Their Applications-A Review Study", Lecture Notes in Electrical Engineering, pp. 31-36, 2016.

[3] O. Mubin, S. Shahid and A. Al Mahmud, "Walk 2 Win: Towards Designing a Mobile Game for Elderly's Social Engagement", Proceeding BCS-HCI '08 Proceedings of the 22nd British HCI Group Annual Conference on People and Computers: Culture, Creativity, Interaction, vol. 2, pp. 11 - 14, 2008.

[4] T. Cota and L. Ishitani, "Motivation and benefits of digital games for the elderly: a systematic literature review", Revista Brasileira de Computação Aplicada, vol. 7, no. 1, pp. 2 - 16, 2015.

[5] J. Mercola, "Is Sweating Good or Bad for Your Health?", Mercola.com, 2017. [Online]. Available:

http://fitness.mercola.com/sites/fitness/archive/2014/01/10/sweatingbenefits.aspx. [Accessed: 27- Jun- 2017].

[6] E. Chilufya, HCI: Design Guidelines of Mobile Device Games for the Elderly, Master Thesis Project 15p, 2014 Spring.

[7] S.F. Wong, "ARCS questionnaire”, Sunway University, 2016.

[8] "Correlation", Socialresearchmethods.net, 2006. [Online]. Available: https://www.socialresearchmethods.net/kb/statcorr.php. [Accessed: 27Jun- 2017]. 